\title{
Chemis3 - Uma Proposta de Jogo para o Ensino de Ciências
}

\author{
Cleon Xavier Pereira Júnior \\ Instituto Federal Goiano, Brazil \\ cleon.junior@ifgoiano.edu.br
}

\author{
Rodrigo Elias Francisco \\ Instituto Federal Goiano, Brazil \\ rodrigo.francisco@ifgoiano.edu.br \\ Geovanna Silva Santos \\ Instituto Federal Goiano, Brazil \\ geovanna488@gmail.com
}

\author{
Zara Hoffmann \\ Instituto Federal Goiano, Brazil \\ zara.hoffman@ifgoiano.edu.br \\ Caroline Pereira \\ Instituto Federal Goiano, Brazil \\ carolcastro_1046@hotmail.com \\ Thaís Almeida Aires \\ Instituto Federal Goiano, Brazil \\ thais.almeida574@gmail.com
}

\begin{abstract}
Resumo-O uso das Tecnologias Digitais de Informação e Comunicação no meio educacional aponta para uma possibilidade de professores e alunos exercerem sua própria cidadania por meio do uso das tecnologias. Neste contexto, o desenvolvimento de ações didáticas diversificadas que aliem saberes cientificos às decisões tomadas no dia-a-dia que estimulem abordagens significativas para compreensão dos conhecimentos científicos, torna-se uma alternativa possível, tanto para o desenvolvimento de sistemas de softwares quanto para o Ensino de Ciências. Dentro de uma proposta de desenvolvimento da criatividade e iniciativa este trabalho tem como objetivo desenvolver um jogo para ser aplicado no Ensino de Ciências. Pretende-se aplicar o protótipo entre os alunos ingressantes, os quais apresentaram grande defasagem de conteúdos científicos, após levantamento diagnóstico.
\end{abstract}

Index Terms—jogo; ensino; química; aprendizagem.

Resumo-The use of Information and Communication Digital Technologies in the educational environment indicates a pos- sibility of educators and students exercise their own citizens through the use of technology. In this context, the development of diversified didactics actions which combine scientific knowledge to decisions taken on a day-to-day that stimulate significant approaches of understanding scientific knowledge, it becomes a possible alternative, both for the development of software systems and for the Science teaching. Within a development proposal of creativity and initiative, this work aims to develop a game format to be applied in Education Science. We intend apply to freshman students, who had presented a large gap of scientific content, after diagnosis survey.

\section{Index Terms-game; chemistry; teaching; learning}

\section{INTRODUCTION}

A tecnologia, de maneira geral, está cada vez mais presente no cotidiano das pessoas. Sua presença cultural aumenta a cada dia, e, com isso, é necessário saber empregá-la em diferentes ambientes, embora tenha o mesmo intuito, o de suprir as necessidades de maneira adequada. As Tecnologias Digitais de Informação e Comunicação (TDICs) visam, dentre outros fatores, levar o acesso universal a educação e aprimorar a qualidade do ensino e aprendizagem 1 . Neste aspecto, mídias digitais podem ser construídas como recurso para disseminar conteúdos de disciplinas de diversas áreas e contribuir com as TDICs na educação.

O termo TDIC, anteriormente conhecido como TIC (Tecnologia da Informação e Comunicação), é usado no contexto educacional para relacionar tanto a educação conectada à internet e seu aspecto social, quanto o uso educacional das tecnologias da informação e comunicação. Duas visões distintas podem definir as tecnologias e seus aparatos na sociedade. Numa visão determinista, conforme [1], tais tecnologias apontam para um conjunto de inovações tecnológicas e, seu conjunto de ferramentas, proporcionam uma redefinição radical do comportamento e funcionamento da sociedade contemporânea. Já na visão instrumentalista de [2], "a tecnologia não determina a sociedade; incorpora-a" visto que há um conjunto de fatores que intervêm nos processos societários, interativos e complexos, como a criatividade e a própria tecnologia. Esta forma de perceber a tecnologia considera-a um instrumento "neutro" utilizada com a finalidade de ter acesso ao conhecimento, também visto como neutro. A essa dualidade de pensamento [3] descrevem como racionalidade instrumental: "um movimento que oscila entre a visão da tecnologia como ferramenta [..] e a atribuição à tecnologia o poder de configurar a cultura e a sociedade", e é esta racionalidade que permeia os projetos pedagógicos de inserção das TICs nos meios educacionais.

A sociedade atual vive a "era da informação"e, consequentemente, a experiência educacional deve ser diversificada, uma vez que envolve multitarefas. Os alunos necessitam dominar o processo de aprendizagem para o desenvolvimento de suas competências, e não mais somente absorver o conteúdo.

Jogos, animações e gráficos são alguns exemplos de mídias digitais que podem ser utilizados como facilitadores durante $\mathrm{o}$ ensino. Mais especificamente, com relação aos jogos, estes podem apresentar o conteúdo de uma forma dinâmica e des- contraída, utilizando de algumas mecânicas, como pontuação ranking, na intenção de gerar uma concentração ao aprendiz. Alguns jogos ainda podem trazer enredos, personagens e diferentes níveis, onde o jogador pode ir conquistando os próximos níveis de acordo com seu desempenho.

A química, introduzida pelo ensino de ciências ainda no nível fundamental, é uma disciplina que estuda as substâncias e as transformações da matéria e faz parte da base curricular de estudantes da educação básica no Brasil. Considerada desinteressante pelos alunos, apesar de estar inserida em nosso cotidiano, seu estudo fica pautado somente por salas de aula sendo que laboratórios e experiências deveriam ser aplicadas no intuito de aprimorar o conhecimento e conduzir o aprendiz a uma vivência prática, vislumbrando a importância de tal ciência. Desta forma, os estudantes seriam possibilitados a ter uma visão crítica do mundo e utilizar o conhecimento para a resolução de problemas atuais e relevantes para sociedade.

Por ser uma ciência de grande importância e complexidade, entende-se que o ensino deve ser pautado de diferentes estratégias visando um aprendizado mais efetivo dos conteúdos por parte dos estudantes. Pelo excesso de conceitos teóricos e 
falta de metodologias alternativas, muitas vezes o estudante é conduzido a uma memorização superficial.

Neste sentido, infere-se que devem ser desenvolvidas ações didáticas diversificadas que aliem saberes científicos a decisões a serem tomadas no dia-a-dia, bem como a busca de abordagens e metodologias que tornem significativos os conhecimentos científicos [4], [5], [6], para que o ensino tecnológico cumpra seu papel na formação de cidadãos comprometidos com a sua comunidade. Com estes pressupostos, pode-se inferir que as atividades de aprendizagem cooperativas, por meio de jogos, simulações e animações, podem proporcionar uma relação dinâmica com o outro e a transformação de um processo interpessoal num processo intrapessoal para a compreensão e solução de problemas. Não se trata mais de acumular conhecimentos, pois "a formação do aluno deve ter como alvo principal a aquisição de conhecimentos básicos, a preparação científica e a capacidade de utilizar diferentes tecnologias relativas à área de atuação" [7]. Dentro destas ações diversificadas, [8] considera que as habilidades e os conhecimentos adquiridos através de jogos, preparam os alunos para melhor desempenho no trabalho e não só para uma profissão específica, mas para a vida em sociedade.

Para uma prática educativa que atenda tanto os requisitos da Inclusão Digital quanto os Parâmetros Curriculares Nacionais para o Ensino Médio (PCNEM), pautada na interdisciplinaridade, contextualização e desenvolvimento de competências e habilidades, não é possível que o professor se atenha ao livro didático apenas, o qual proporciona um entendimento periférico e fragmentado dos conhecimentos [7]. Em busca de uma estratégia motivacional para o ensino de ciências, abordando conceitos químicos presentes no ambiente, este trabalho propõe um jogo como metodologia complementar, visando representar conceitos teóricos de uma forma dinâmica, tentando suprir a carência de vivências práticas e e de aulas experimentais.

Este trabalho está dividido como se segue. A seção II apresenta os trabalhos relacionados, que trazem jogos como estratégia para complementar o ensino de conteúdos da educação básica. A seção III apresenta a proposta do jogo Chemis3 para o ensino de química, através de substâncias químicas presentes no meio ambiente. A seção IV apresenta os resultados da avaliação de uma turma de estudantes da educação básica acerca do jogo e também a avaliação realizada por alguns professores que trabalham com a educação básica. Por fim, a seção V traz as considerações finais e trabalhos futuros.

\section{TRABALHOS RELACIONADOS}

Ao fazer uma busca acerca de jogos para o ensino em geral, é possível notar uma boa aceitação destes e, além disso, é visível uma grande aplicação nas áreas de ciências exatas e naturais. $\mathrm{O}$ ensino de humanidades apresenta uma menor quantidade nas aplicações no formato de jogo como suporte para as atividades ministradas em sala de aula. Além disso, uma revisão de trabalhos sobre o tema [9] aponta que a partir de 2006 houve um crescimento na adoção de jogos para a aprendizagem. Os trabalhos levantados na pesquisa apontam os jogos para trabalhar conceitos, processos científicos, resolução de problemas, afetividade, engajamento ou aprendizagem contexto-social.

No ensino de história, é possível encontrar algumas iniciativas através de jogos. O Tríade - igualdade, liberdade e fraternidade [10] apresenta como roteiro a revolução francesa e é voltada para estudantes do ensino fundamental II. O jogo é no formato RPG, onde quem escolhe o caminho que quer seguir é o jogador e não o roteirista. É interessante analisar neste jogo, além do seu conteúdo educativo, o formato que é apresentado. Jogos de RPG apresentam sucesso no meio dos jogadores que o utilizam como forma de entretenimento. Há uma gama de jogadores que se divertem com este formato de jogo. Neste caso, não há um ganhador.

Outro jogo que trata de contexto histórico foi apresentado por [11]. Este jogo permite que estudantes explorem a história de Amsterdã, andando pela cidade, através de personagens, e trocando informações via celulares com GPS. Neste caso, há um jogo no estilo de realidade aumentada, que utiliza recursos modernos para entreter o aprendiz. Tal aplicação possibilita ver o potencial de dispositivos móveis para auxiliar no ensino através de jogos. A realidade aumentada é um recurso que tem ganhado bastante espaço nos últimos tempos, principalmente em aplicações de jogos.

$\mathrm{Na}$ área de biologia, [12] apresenta o jogo para o ensino das leis de Mendel. O jogo foi desenvolvido em game maker. Através de interações com os usuários há uma demonstração dos cruzamentos básicos de acordo com as leis de mendel. Posteriormente o jogo foi passado por uma avaliação, conforme apresentado por [13] e, através dos resultados, é possível enxergá-lo como um utilitário no ensino das leis mendelianas em genética.

Mais específico para o ensino de química, existe uma gama de trabalhos que demonstram o uso de jogos para maior efetividade do ensino. [14] é outro exemplo da realidade aumentada aplicada a jogos. Neste caso, a tabela periódica é o alvo de estudo e esta é apresentada, através da realidade aumentada, para um jogo colaborativo que, enquanto os jogadores se divertem, aprendem sobre os elementos da tabela periódica.

Já [15] apresenta o uso de um jogo de tabuleiro para o reforço dos conceitos básicos de química. Neste caso é um jogo não-digital, demonstrando a possibilidade do uso de adaptações de jogos do dia-a-dia de crianças e adolescentes para o ensino. O jogo de tabuleiro permite uma interação física e um entretenimento, sendo que este formato de jogo já é utilizado por muitas gerações e permeiam até os tempos atuais.

Visando ensinar fotossíntese e respiração celular aeróbica, foi criado um jogo [16] que não utiliza TIC. O jogo se mostrou bastante positivo, levando aos alunos a tomarem decisões e formarem uma rede de negociação, sendo que em alguns momentos foi necessária a intervenção do professor.

O ensino de cálculo da frequência cardíaca em repouso, que envolve matemática e biologia, foi realizado usando os jogos Kinect Sports e Just Dance do Xbox 360o com Kinect [17], e apresentou a possibilidade de explorar as inteligências múltiplas e estimular o raciocínio lógico, a atenção e a construção de conceitos. Para trabalhar com o conteúdo de biosegurança foi proposto o jogo Chemical Risk [18], que inclui em sua interface labirinto, salas, luvas, óculos de proteção e ajuda o aluno a exercitar e fixar o conteúdo aprendido em sala de aula. De um modo geral, percebe-se, a partir da literatura es- tudada, que os jogos para o ensino de ciências, apesar de não serem restritos a TIC, são facilitados por esta. A partir da análise de trabalhos já desenvolvidos, foi possível ver aplicações móveis com realidade aumentada, jogos no formato de RPG, jogos de plataforma, uso de consoles (no caso o xbox), dentre outros. Desta forma, é notado que os jogos para educação costumam apresentar um foco diferente, porém com as mesmas estruturas encontradas em jogos para entreteni- mento.

Os exemplos apresentados evidenciam o sucesso do uso de tais estratégias para aprendizagem de contextos que envolvam conteúdos de várias áreas, sendo que estes podem ser aplicados para efetivar a aprendizagem e aprofundar um conhecimento 
passado em sala de aula.

Quanto à concepção dos jogos, estes precisam estar ancorados em conhecimentos científicos da área de aplicação, como a química, e conceitos educacionais, como gamificação, motivação, criatividade, engajamento e trabalho em equipe. No entanto, é preciso de planejamento didático para que haja sucesso no uso das ferramentas, pois o sucesso depende de fatores culturais que precisam ser pensados de maneira ecossistêmica [19].

\section{CHEMIS3 - UM JOGO PARA SUPORTE AO} ENSINO DE CIENCIAS

Este artigo visa apresentar uma proposta de jogo como ferramenta adicional para o ensino de ciências. O CHEMIS3 (parte do termo inglês Chemistry, cujo significado é química) se trata de um jogo educacional para a área das substâncias Químicas, como o nome sugere.

Caracterizado como uma pesquisa qualitativa, este trabalho foi desenvolvido com a utilização de diversas estratégias de investigação. A princípio foram utilizados dados da avaliação diagnóstica efetuada pelos professores com alunos ingressantes, com a finalidade de detectar suas dificuldades específicas. Esta investigação permitiu determinar o nível de conteúdo científico a ser trabalhado no jogo, sendo a química e a educação ambiental escolhido como foco principal.

Após esta investigação inicial, permitiu-se realizar uma pesquisa exploratória, fazendo um levantamento bibliográfico acerca do assunto, como objetivo de verificar o que já existia na literatura e ampliar as ideias da ferramenta que seria construída. $\mathrm{O}$ desenvolvimento do jogo foi acompanhado por especialistas das áreas de química e biologia. Desta forma, a combinação de resultados apontados na literatura com conhe- cimentos de especialistas torna o jogo mais realista para o uso por parte de estudantes e aceitação por parte de professores.

A documentação foi baseada no Game Design Document (GDD), conforme esperado no desenvolvimento de um jogo. O GDD permite fazer um direcionamento do jogo e é um documento escrito pelo game designer. No GDD desenvolvido nesta pesquisa, foi possivel descrever o enredo e as funções de cada tecla utilizável no jogo, funcionando como um guia para desenvolvedores, jogadores e designers.

$\mathrm{O}$ enredo conta com um personagem chamado Caio que está a caminho de casa e possui alguns obstáculos. Para atingir seu objetivo, ou seja, chegar em casa antes do anoitecer, o personagem deve resolver algumas questões que envolvem elementos químicos. No exemplo apresentado pelas figuras 1 , 2 e 3 o Caio se depara com um incêndio no caminho, porém anteriormente ele já havia atravessado um rio e é uma região que ocorre bastante chuva. Naquele momento, para que Caio continue o seu trajeto ele deve responder qual o elemento predominante na chuva. Ao selecionar a substância da água, a chuva ocorre, eliminando o fogo que estava prejudicando a natureza e permitindo que o Caio continue com seu objetivo. Todos os obstáculos apresentados no jogo seguem o mesmo padrão. A princípio há um desafio, para tentar resolver este desafio a tecla "s"deve ser pressionada. Ao apertar a tecla, a dica para a solução do desafio é apresentada e o jogador tem uma única chance de tentar resolvê-lo. Ao resolver corretamente o jogador pode avançar. Além disso, sempre aparece um quadro no estilo "curiosidades"explicando o motivo de tal fenômeno (figura 4).

Para o desenvolvimento do jogo, foi utilizado o Game Maker: Studio. A ferramenta permite a criação de jogos no estilo 2D e apresenta uma interface de fácil uso para desenvolvedores. $\mathrm{O}$ jogador visualiza o jogo em terceira pessoa, onde ele pode ver o ambiente, os obstáculos e o próprio personagem de uma distância razoável. Estes três componentes são vistos simultaneamente.

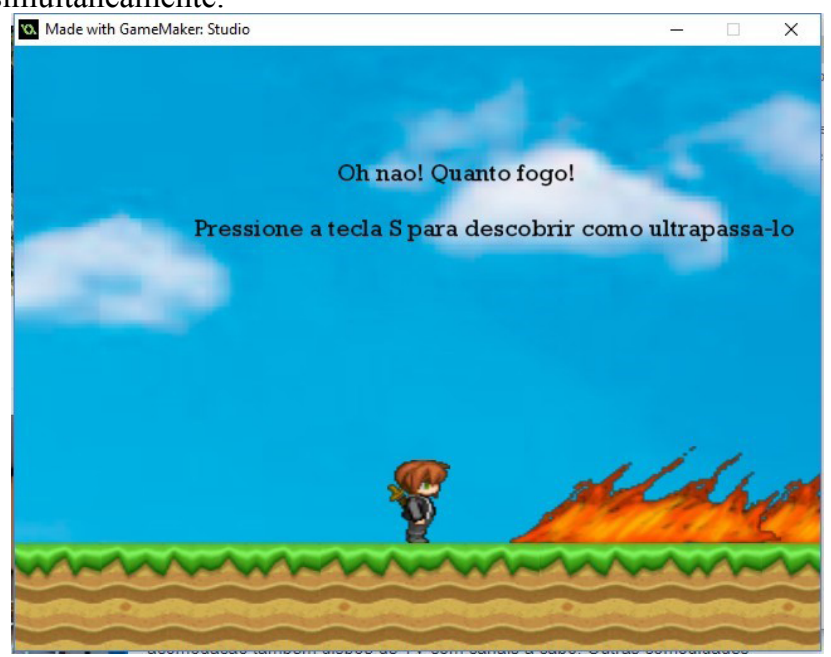

Figura 1. Personagem em frente ao obstáculo

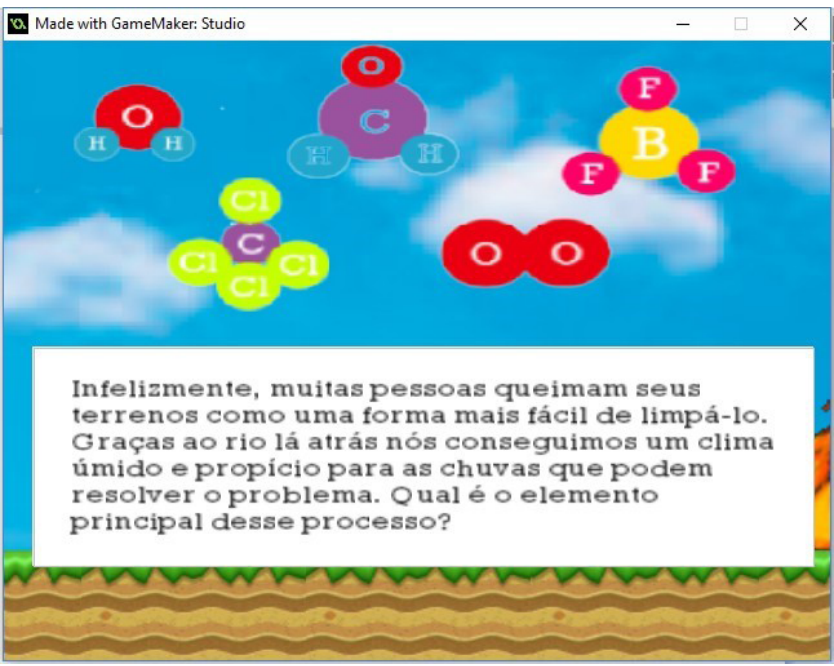

Figura 2. Personagem resolvendo o desafio

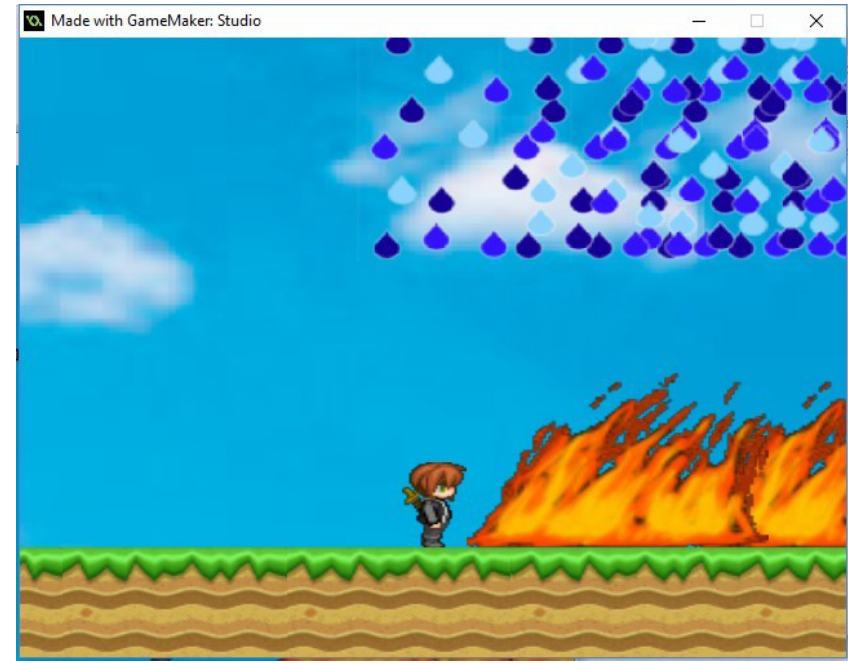

Figura 3. Personagem podendo avançar após desafio resolvido

O jogo possui três fases curtas e permite ao aprendiz reforçar conceitos das substâncias químicas, além de ver a importância destes no meio ambiente. Através do jogo é possível verificar que é necessário a existência de árvores para a respiração, das flores para o controle das colmeias, etc. $\mathrm{O}$ jogo pode ser resolvido com alguns minutos de dedicação (em torno de 20 a 30 minutos) e apresenta bastante conhecimento durante a resolução. Ao final, o 
personagem Caio chega em sua casa, conforme figura 5 .

a Made with GameMaker: Studio

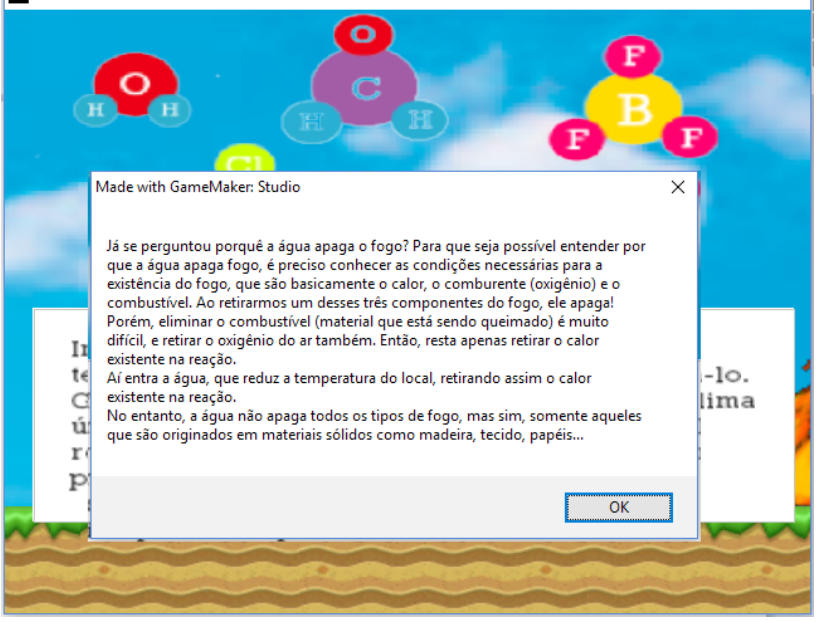

Figura 4. Tela explicando o fenômeno da chuva e fogo

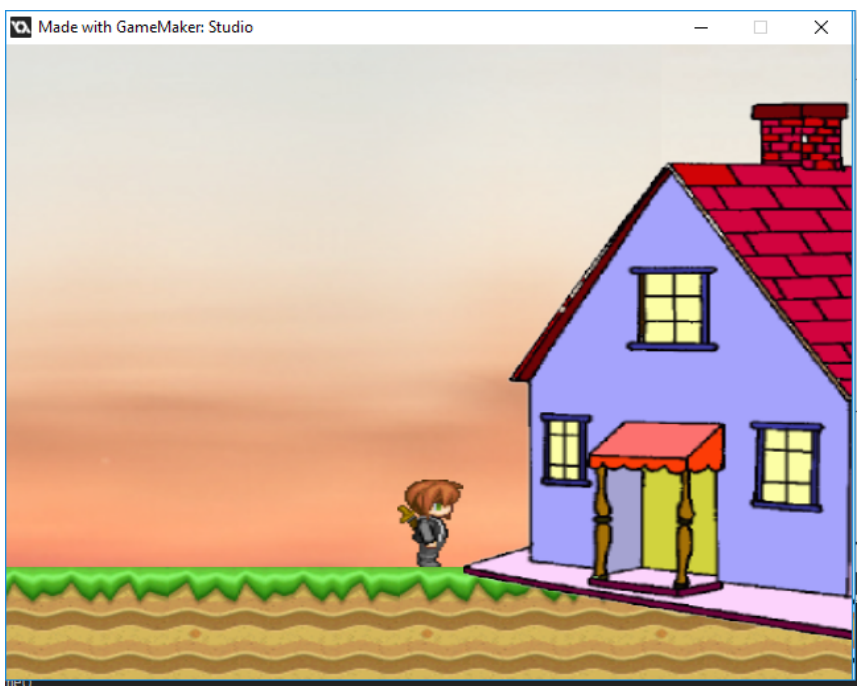

Figura 5. Caio chegando em sua casa (objetivo do jogo)

\section{AVALIAÇÃO}

Por se tratar de um jogo educacional, foi aplicado um questionário para 27 estudantes voluntários que cursavam o ensino médio em uma escola pública no Brasil e para 5 educadores envolvidos no processo de aprendizagem de estudantes da educação básica (Professores e pedagogos).

O questionário utilizado para a avaliação foi o MEEGA+. Este modelo foi desenvolvido para avaliar a qualidade dos jogos utilizados para o ensino de computação / Engenharia de Software sob o ponto de vista dos estudantes [20]. Ao fazer uma análise do questionário, pôde ser observado que o mesmo, apesar de ser desenvolvido para fins de avaliação de jogos no ensino de computação, não trazia nenhuma limitação para o jogo apresentado neste trabalho.

O questionário fornece por padrão 36 afirmações (Conforme Tabela I) e o jogador deve marcar se concorda, concorda totalmente, discorda, discorda totalmente ou nem concorda e nem discorda. Além do questionário, junto ao kit MEEGA+, é fornecida uma planilha de dados que, ao lançar as respostas do estudante, permite fazer uma análise do jogo acerca de usabilidade, confiança, desafio, satisfação, interação social, diversão, atenção focada, relevância, aprendizagem de curto prazo e objetivos de aprendizagem.

Uma vez que os pedagogos e professores estão envolvidos no processo da educação e o jogo envolve questões educacionais, o mesmo questionário foi submetido para alguns educadores na intenção de verificar a visão dos mesmos acerca do jogo. Esta seção apresenta duas partes, sendo a primeira com o resultado dos alunos e as observações acerca disto e a segunda com o resultado dos educadores e também algumas conclusões a respeito.

\section{A. Avaliação dos estudantes}

Os dados fornecidos pelos estudantes foram tabulados e dois gráficos foram gerados. A Figura 6 traz um gráfico com relação à experiência do jogador.

Através do gráfico é possível perceber que a usabilidade foi considerada agradável em quase todos os pontos, exceto personalização e prevenção de erros do jogador. O jogo também não promove interação social e foi um ponto negativo na avaliação. O jogo foi desenvolvido para jogar individual- mente e local, não permitindo interação com outros jogadores.

TABLE I : AFIRMAÇÕES DO QUESTIONÁRIO

\begin{tabular}{|c|c|}
\hline Na Ifem & Descricio Item \\
\hline $\mathrm{T}$ & O design do jopo é air $x$ nk (tabuleiro, carias, etc) \\
\hline 2 & $\begin{array}{l}\text { Os bextos, cones e fonles combinam e } \leq 10 \\
\text { consistenies. }\end{array}$ \\
\hline 3 & $\begin{array}{l}\text { Ea paeciei aprender poucas coisas para poder } \\
\text { comecar a jogar o jogo }\end{array}$ \\
\hline 4 & Apoender a jogar este jogo foi ficil para mim. \\
\hline 5 & $\begin{array}{l}\text { Eu acho que a máoria das pessoas aprenderiam } \\
\text { a jopar este jopo rapidamente. }\end{array}$ \\
\hline 6 & Eu considero que o jogo é facil de jogar. \\
\hline 7 & As $\pi$ gras do jogo sa claras e compreensiveis. \\
\hline 8 & $\begin{array}{l}\text { As fontes (tamanho e estilo) utilizadas no jogo } \\
\text { sto legiveis. }\end{array}$ \\
\hline 9 & As cons utilizadas no jogo sso comparensiveir. \\
\hline 10 & $\begin{array}{l}\text { O jogo permibe personalivar a aparíncia (fonle } \\
\text { dou cor) conforme a minha necessidak. }\end{array}$ \\
\hline TI & O jogo me protege de comeler erros \\
\hline 12 & $\begin{array}{l}\text { Quando eu cometo um erro é fäcil de me } \\
\text { recuperar rapidamente. }\end{array}$ \\
\hline 13 & $\begin{array}{l}\text { Quando olhei pela primeira vez o jogo, eu tive } \\
\text { a impressio de que seria ficil para mim. }\end{array}$ \\
\hline 14 & $\begin{array}{l}\text { A organizaçio do conieúdo me ajodou a estar } \\
\text { confiante de que eu iria aprender com este jogo. }\end{array}$ \\
\hline 15 & Fsle jogo é adequadamenie desafiador para mim. \\
\hline 16 & $\begin{array}{l}\text { O jogo ofencoe novos desafios (oberex novos } \\
\text { obstaculos, situaçbes ou variagbes) com um } \\
\text { rìmo adequado. }\end{array}$ \\
\hline 17 & $\begin{array}{l}\text { O jogo nbo se toma monótono nas suas taxefas } \\
\text { (mpetitivo ou com taxefas chatas). }\end{array}$ \\
\hline 18 & $\begin{array}{l}\text { Completar as tarefas do jogo me deu um } \\
\text { sentimento de realiz actio. }\end{array}$ \\
\hline 19 & $\begin{array}{l}\text { E devido an meu esforpo pessogal que eu } \\
\text { consigo as ancar no jogn. }\end{array}$ \\
\hline 20 & $\begin{array}{l}\text { Me sinito satisfeito com as coisas que apoendi } \\
\text { no juga. }\end{array}$ \\
\hline 21 & Eu zecomendaria este jogo para meus colegas \\
\hline 22 & Eu pode inheragir com oukrs pessows durante o jogo \\
\hline 23 & $\begin{array}{l}\text { O jogo promove momentas de cooperapio elou } \\
\text { competipas entre as jogadores. }\end{array}$ \\
\hline 24 & $\begin{array}{l}\text { Eu me senti bem inkeragindo com outras pessous } \\
\text { durante o joge }\end{array}$ \\
\hline 25 & Eu me diverti com o joge \\
\hline 26 & $\begin{array}{l}\text { Aconteceu alguma sítuaçso daranie o jogo } \\
\text { (elementos do jogo, competiçán, etc) que } \\
\text { me fez sorrit }\end{array}$ \\
\hline $\boldsymbol{Z} z$ & $\begin{array}{l}\text { Howve algo interessante no inicio do jogo que } \\
\text { capturou minha atencân. }\end{array}$ \\
\hline 28 & $\begin{array}{l}\text { Eu estava ta envolvido no jogo que eu pendi a } \\
\text { nogán do tempe. }\end{array}$ \\
\hline 29 & $\begin{array}{l}\text { Eu esqueci sotire o ambienile ao meu redor } \\
\text { enquanto jogrva este jogo. }\end{array}$ \\
\hline 30 & $\begin{array}{l}\text { O conteúdo do jogo é relevante para os meus } \\
\text { interesses. }\end{array}$ \\
\hline 31 & $\begin{array}{l}\text { E claro para mim camo o conbébo do jogo estí } \\
\text { relacionado com a disciplina }\end{array}$ \\
\hline 32 & $\begin{array}{l}\text { O jogo é um método de ensino adequado para } \\
\text { esta disciplina. }\end{array}$ \\
\hline 33 & $\begin{array}{l}\text { Eu pofiro aprender com este jogo do que de } \\
\text { outra forma (outro método de ensino). }\end{array}$ \\
\hline 34 & $\begin{array}{l}\text { O jogo concibauiu para a minha aprendiragem } \\
\text { na disciplina. }\end{array}$ \\
\hline 35 & $\begin{array}{l}\text { O jogo foi ebciente para minha apoendivagem, } \\
\text { em comparacto com outrs atividades da } \\
\text { disciplina }\end{array}$ \\
\hline 36 & $\begin{array}{l}\text { O jogo contribuiu para zeforçar conceitcos, } \\
\text { de ligaçbes quimica no meio ambiente. }\end{array}$ \\
\hline
\end{tabular}


Quanto a atenção focada, as respostas foram bem divididas. Houveram estudantes que concordaram que o jogo prendia a atenção a ponto de desligar do que ocorria ao redor, por outro lado alguns estudantes discordaram . Talvez a divisão de respostas tenha sido consequência da forma de aplicação (Em um laboratório de informática com espaço reduzido).

Com relação à satisfação e relevância, as respostas demonstraram que os itens foram vistos de forma positiva pelos estudantes. Por exemplo, 26 estudantes concordaram ou concordaram fortemente que o conteúdo está relacionado a disciplina de química, o que leva a concluir que é possível extrair uma aprendizagem. A maioria também afirmou que o conteúdo do jogo era relevante para os interesses. Outro ponto positivo observado a partir das respostas do questionário é que

o jogo foi encarado como desafio pela maioria dos estudantes. Isto deve tornar o jogo mais atraente do ponto de vista didático.

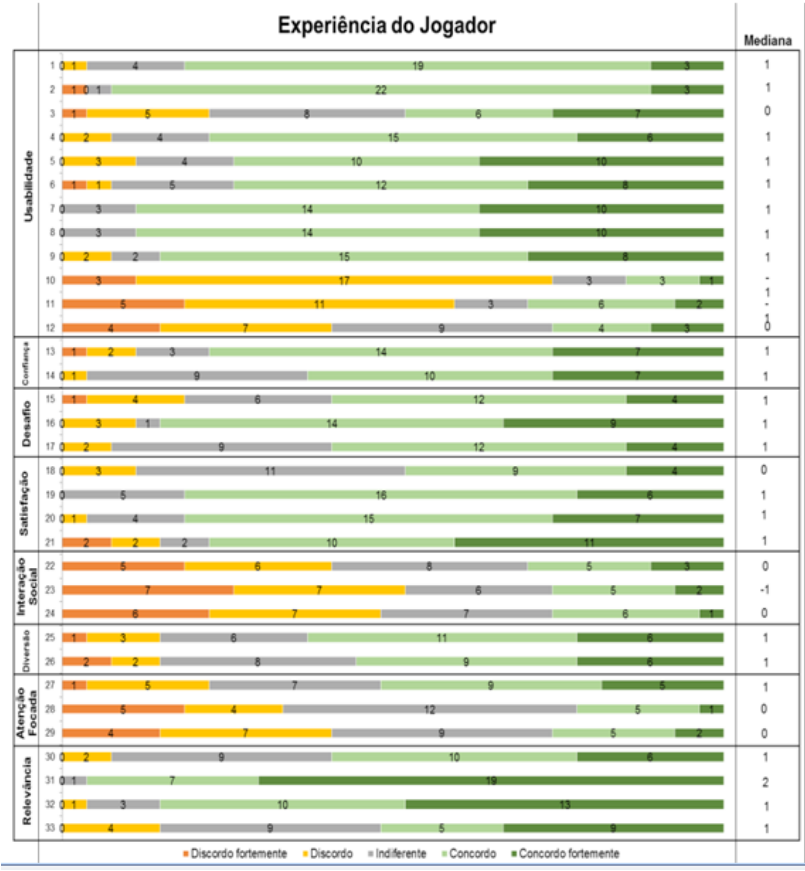

Figura 6. Gráficos com resultados da experiência do aluno jogador)

O segundo gráfico (Figura 7) apresenta uma classificação de acordo com a aprendizagem do estudante. Foram realizadas apenas três perguntas, sendo que é possível verificar um pouco com relação à aprendizagem curta.

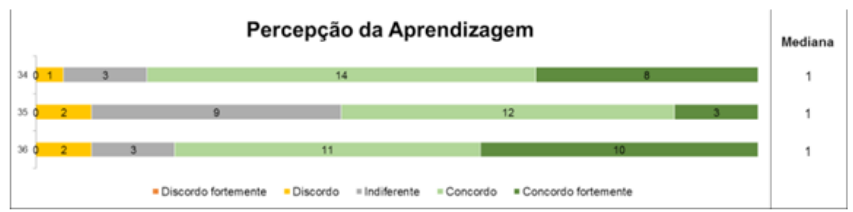

Figura 7. Gráfico com os resultados acerca da percepção de aprendizagem dos alunos jogadores.)

As três perguntas revelaram que a aprendizagem através deste jogo apresentaram pontos positivos. Todas elas tiveram maioria concordando ou concordando fortemente, o que traz um incentivo a mais em investir em tais práticas como complemento da aprendizagem.

\section{B. Avaliação dos educadores}

Da mesma forma que ocorreu com os estudantes, os dados fornecidos pelos educadores também foram tabulados e gerado gráficos. Ao comparar os dois resultados é possível ver que há uma semelhança nos gráficos.

Com relação a usabilidade, de uma forma geral, a maioria das questões sobre este item foram bem avaliadas, como observado no gráfico, com exceção para a personalização dos componentes, como fonte e cores, e para a recuperação do nível rapidamente após cometer algum erro. Já justificado na avaliação dos estudantes, realmente o jogo é estático e não permite nenhum tipo de personalização.

Já a Confiança, o nível de percepção sobre a impressão de aprender facilmente os conteúdos e com a interface do jogo foi satisfatório. Com relação ao desafio, há uma crítica sobre a monotonia e a falta de desafios suficientes para satisfazer o jogador. O item Satisfação apresenta um resultado positivo. De acordo com os professores, o jogo é de fácil aceitação e pode ser recomendado aos colegas.

Contradizendo um pouco a opinião dos alunos, de acordo com os professores, apesar de ser lúdico, o jogo não oferece alternativas à diversão e não chama atenção por não oferecer novos desafios e recompensas. O jogo oferece conteúdos de aprendizagem de relevância dentro da disciplina e é aceitável para fixar os mesmos.

De acordo com a avaliação, de $75 \%$ dos respondentes, o jogo oferece uma alternativa para a aprendizagem dos conteúdos propostos, sendo preferível ã qualquer outra ati- vidade dentro da disciplina e é satisfatório para contribuir na aprendizagem cognitiva (figura 9).

Além disso, foi deixado um espaço aberto para que houvessem sugestões de melhorias por parte dos educadores.Algumas sugestões mais emergentes são:

- Ter um guia com explicações como jogar;

- Dar pontuação ao jogador como estratégia de motivação pelos acertos;

- Ter textos com menos caracteres e mais lúdicos quando o jogador acerta;

- Ter opção para acelerar o personagem;

- Ter mais obstáculos para tornar o jogo mais desafiador.

\section{CONSIDERAÇÕES FINAIS}

Este trabalho apresentou uma mídia digital no formato de jogo, como ferramenta auxiliar para o ensino de ciências (mais específico, para o ensino de química) através de elementos presentes na natureza. O jogo foi inspirado pela dificuldade apresentada por estudantes com relação aos conceitos que envolvem ciências naturais e pela importância da mesma no cotidiano.

Ao desenvolver um jogo educacional, ocorrem dois desafios: o primeiro deve-se aos conceitos que envolvem o jogo. É necessário levar em consideração elementos como usabilidade (sons, cores, gráficos, etc), jogabilidade, desafios, confiança, entre outros. Neste aspecto, o jogo apresentou alguns déficits, segundo avaliação dos estudantes. O mesmo é um jogo indi- vidual e o colaborativismo é visto como positivo na educação, sendo que o mesmo pode ser aplicado em versões futuras. Também não é possível personalizar o jogo, criar avatares distintos e alterar os sons. Mas, no geral o jogo conseguiu atender bem o público que estava avaliando.

O segundo desafio é com relação ao conteúdo. Junto ao entretenimento dos jogos, é necessário levar uma aprendizagem ao jogador. Neste caso, a avaliação foi feita em torno de três 
afirmações que demonstraram que o objetivo do jogo neste aspecto foi atingido.

O jogo atualmente possui somente três fases e não é permitido que o jogador continue de onde parou. Para as próximas versões serão melhorados estes aspectos e outros observados pelos avaliadores. Apesar de não ser uma ferramenta ainda tão aceita como recurso educacional, os jogos podem atrair públicos mais jovens e permitir um reforço de aprendizagem de uma forma mais divertida e dinâmica, em diferentes ambi- entes, não presos somente aos recursos existentes em sala de aula.

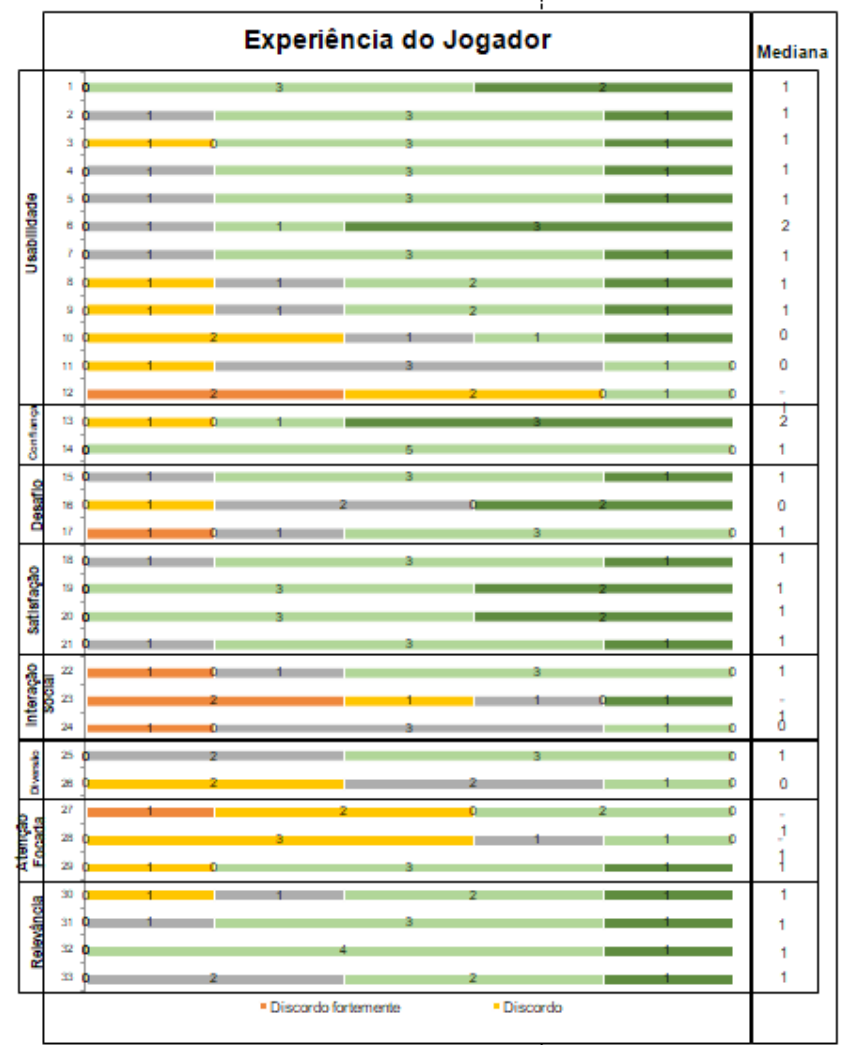

Figura 8. Gráficos com resultados da experiência do educador jogador)

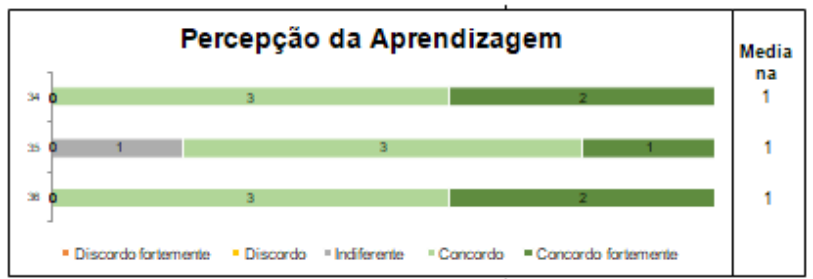

Figura 9. Gráfico com os resultados acerca da percepção de aprendizagem dos educadores jogadores.)

As avaliações submetidas para educadores e estudantes geram satisfação em continuar pesquisando e desenvolvendo sobre jogos na educação. $\mathrm{O}$ mercado de jogos como entretenimento é crescente e o uso de smartphones têm impulsionado este crescimento. Investir em jogos que podem ser usados em dispositivos móveis devem ser uma tendência, visto que estes permitem o acesso em qualquer lugar e a qualquer hora.

Este trabalho apresenta uma contribuição para a pesquisa de Informática na Educação através da construção de um jogo. É preciso ser planejado recursos distintos, tais como jogos, para a educação como forma de sempre alavancar a aprendizagem.

\section{REFERENCES}

[1] M. A. Hato Sánchez and S. T. Vargas Lema, "El uso de las tics como instrumento pedagógico en el proceso educativo de los estudiantes de bachillerato en químico biólogo del i.t.s. república del ecuador durante el año lectivo 2011-2012," 2013.

[2] M. Castels and A. S. em Rede, "A era da informação: economia, sociedade e cultura," São Paulo: Paz e Terra, vol. 3, 1999.

[3] J. Peixoto and C. H. dos Santos Araújo, "Tecnologia e educação: algumas considerações sobre 0 discurso pedagógico contemporâneo," Educação \& Sociedade, vol. 33, no. 118, pp. 253-268, 2012.

[4] A. I. Chassot, A educação no ensino da química. Unijuí, 1990.

[5] E. F. Mortimer, Linguagem e formação de conceitos no ensino de ciências. UFMG, 2000.

[6] A. Cachapuz, J. Praia, and M. Jorge, "Da educação em ciência às orientações para o ensino das ciências: Um repensar epistemológico from science education to science teaching: an epsitemological rethinking,"Ciência \& educação, vol. 10, no. 3, pp.363-381, 2004.

[7] M. SEMTEC, "Parâmetros curriculares nacionais para o ensino médio,"Brasília: Secretaria deEducação Média e Tecnologia, 1999.

[8] I. Chateau, Jogo E a Criança, O. Grupo Editorial Summus, 1987.

[9] M.-C. Li and C.-C. Tsai, "Game-based learning in science education: a review of relevant research," Journal of Science Education and Technology, vol. 22, no. 6, pp. 877-898, 2013.

[10] C. Santana, G. Sena, J. MOURA, and L. Alves, "Tríade: delineando o processo de construção de um roteiro de um jogo eletrônico," Anais do VI SBGames, vol. 7, 2006.

[11] S. Akkerman, W. Admiraal, and J. Huizenga, "Storification in historyeducation:Amobilegameinand aboutmedievalamsterdam," Compu- ters \& Education, vol. 52, no. 2, pp. 449-459, 2009.

[12] J. S. de Lima and V. A. dos Santos, "Jogo leis de mendelensinando genética de forma lúdica," in Brazilian Symposium on Computers in Education (Simpósio Brasileiro de Informática na Educação-SBIE), vol. 25, no. 1, 2014, p. 677.

[13] J. Soares and A. Rodrigues, "Avaliação do jogo educativo lei de mendel," in Brazilian Symposium on Computers in Education (Simpósio Brasileiro de Informática na Educação-SBIE), vol. 27, no. 1, 2016, p. 826.

[14] C. Boletsis and S. McCallum, "The table mystery: An augmented reality collaborative game for chemistry education," in Serious Games Development and Applications. Springer, 2013, pp. 86-95.

[15] K. Capps, "Chemistry taboo: An active learning game for the general chemistry classroom," Journal of chemical education, vol. 85, no. 4, p. 518, 2008.

[16] L. M. d. J. B. Gomes and J. C. Messeder, "Fotossíntese e respiração aeróbica: vamos quebrar a cabeça? proposta de jogo," Revista de Ensino de Bioquímica, vol. 12, no. 2, pp. 91-107, 2014.

[17] C. S. d. Oliveira, "Jogos no ensino das ciências e a neuroeducação na educação básica," 2015.

[18] C. N. de Albuquerque, L. F. de Souza, W. A. de Moura, D. M. da Silva Oliveira, G. K. da Silva, and A. G. Rodrigues, "Chemical risk: Criação de um jogo didático para o ensino de biossegurança," Revista de Graduação USP, vol. 1, no. 2, pp. 69-74, 2016.

[19] D. Cavallo, H. Singer, A. S. Gomes, I. I. Bittencourt, and I. F. Silveira, "Innovation and creativity on basic education: From concepts to the ecosystem," Brazilian Journal of Computers in Education, vol. 24, no. 02, p. 143, 2016.

[20] G. Petri, C. G. von Wangenheim, and A. F. Borgatto, "Meega+: an evo- lution of a model for the evaluation of educational games," INCoD/GQS, vol. 3, 2016. 